\title{
Climatic factors, parity and total number of pigs born associated with occurrences and numbers of stillborn piglets during hot or cold seasons in breeding herds
}

\author{
Satomi Tani, Ryosuke lida and Yuzo Koketsu* \\ *Correspondence: koket001@isc.meiji.ac.jp

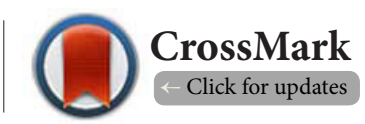

School of Agriculture, Meiji University, Higashi-mita 1-1-1, Tama-ku, Kawasaki, Kanagawa, Japan.

\begin{abstract}
Our objective was to examine interactions between climatic factors and either parity or total number of pigs born for the occurrence of sows having stillborn piglets (SBP) and on the number of SBP, during two seasons. Datasets included 161,299 parity records from 101 herds located in a humid subtropical climate zone; all the sows farrowed either between June and September (hot and humid season) or between December and March (cold season). The climate data were obtained from 21 weather stations located close to the herds. For each parity record, average daily maximum (HT) and minimum temperatures (LT) for the farrowing date and the previous day were coordinated with the performance data. Multilevel logistic regression and Poisson regression models were conducted for whether or not a sow had SBP in a given litter, and for the number of $\mathrm{SBP}$ by sows that had farrowed at least one SBP, respectively. The occurrences $( \pm \mathrm{SEM})$ of sows having SBP during the hot and humid season and during the cold season were $49.6 \pm 0.17 \%$ and $48.8 \pm 0.18 \%$, respectively.

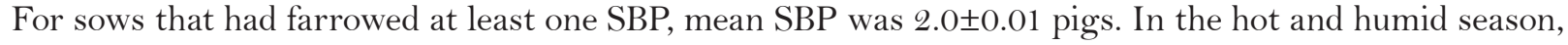
the occurrences of parity 3 or higher sows having SBP increased by $2.1-2.7 \%$ as HT increased from 25 to $30^{\circ} \mathrm{C}(\mathrm{P}<0.05)$, but $\mathrm{HT}$ was not associated with the occurrences of parity 1-2 sows having $\mathrm{SBP}(\mathrm{P}=0.73)$. Also, a sow exposed to $30^{\circ} \mathrm{C}$ had 0.04 more $\mathrm{SBP}$ than one exposed to $25^{\circ} \mathrm{C}(\mathrm{P}<0.05)$.In the cold season, the occurrences of sows having SBP in any parity group increased by $0.9-2.2 \%$ as LT decreased from 5 to $0^{\circ} \mathrm{C}$ $(\mathrm{P}<0.05)$. Also, as LT decreased from 5 to $0^{\circ} \mathrm{C}$, the occurrences of sows having SBP and the number of SBP for sows that farrowed 16 pigs (90th percentile) increased by $2.7 \%$ and 0.09 pigs, respectively $(\mathrm{P}<0.05)$. Taking into account parity and total number of pigs born, HT in summer and LT in winter appear to be critical for the occurrence of SBP and for the number of SBP.
\end{abstract}

Keywords: Cold stress, hot weather, relative humidity, stillbirth

\section{Introduction}

Concurrently with selection for increased total number of pigs born, there have also been increases in both the occurrence of sows having stillborn piglets (SBP) and the average number of SBP per farrowing $[3,19]$. A major cause of SBP is asphyxia or hypoxia, which occurs frequently in dystocia cases $[5,6]$. A study of piglet deaths recorded as SBP found that $70-75 \%$ died during delivery, and the remainder died shortly before, or immediately after farrowing [5]. In practice, SBP in commercial herds are categorized as piglets found dead behind the sow at the first check up after parturition, with no sign of decomposition $[\mathbf{9}, \mathbf{1 9}]$.
Both higher parity andmore total number of pigs born per sow have been associated witha higher occurrence of a sow having SBP $[10,19]$ or a higher number of SBP $[9]$. It has also been suggested that high temperature in farrowing units at parturition may be anotherfactor associated with more SBP or more sows having SBP $[13,19]$.

Ambient temperatures measured at local meteorological stations have been shown to be associated with reproductive performance parameters, such as occurrences of returns to service, farrowing rate and gilt age at puberty $[2,7,17]$. However, no studies have quantified associations between climatic factors (temperature and relative humidity) and either the occurrence 
Tani et al. Veterinary Medicine and Animal Sciences 2016,

of a sow having SBP or the number of SBP. Nor have they examined interactions between climatic factors and either parity or total number of pigs bornin relation to SBP. In addition to unknown risk of high temperatures on SBP, there is also no information about the effect of low temperatures on either the occurrence of a sow having SBP or on the number of SBP. Therefore, the objective of this study was to examine and quantify interactions between climatic and production factors for both the occurrence of a sow having SBP and the number of SBP, during eithera hot and humid season or a cold season.

\section{Materials and methods \\ Herds}

One hundred and eleven pig producers in Japan that use the PigCHAMP recording system (PigCHAMP, Ames, IA, U.S.A.) were requested to mail their data files to Meiji University in 2010. By August 31, 2010, data files were received from 103 breeding herds located throughout Japan in either humid subtropical (98 herds) or humid continental climate zones (5 herds). Two of the herds were excluded from the present study because they were producing only purebred pigs, so data from 101 commercial breeding herds were used in the study. Natural or mechanical ventilation was used in the farrowing barns of these herds. Females in the herds were mainly crossbreds between Landrace and Large White, either produced within the herds or they were replacement gilts purchased from national or international breeding companies. The breeding stocks in the national breeding companies were originally imported from the U.S.A or Europe.

Data for herd size and pigs weaned per mated female per year were abstracted from the 101 herd data files, for three 1 -year periods from 2007 to 2009. Mean ( \pm SEM) herd size was $427 \pm 57.3$ females, ranging between 50 and 3,640 females. Also, mean pigs weaned per mated female per year was $22.6 \pm 0.18$ pigs, with a range from 15.8 to 26.4 pigs.

\section{Sow reproductive performance data}

Data for sows farrowed between June and September (hot and humid season) and between December and March (cold season) in 2007, 2008 and 2009 were extracted from the PigCHAMP recording system. Two datasets were created for the present study. One dataset was created for the occurrence of a sow having SBP. This dataset contained 81,678 parity records of 57,753 sows farrowed in the hot and humid season and 79,634 parity records of 55,707 sows farrowed in the cold season. Records of sows with zero-total pigs born were excluded (13 records), resulting in a total of 161,299 parity records of sows farrowed in either the hot and humid or cold season. A second dataset was also created to study the number of SBP. This dataset omitted the records of females with zero SBP (81,903 records), and thus comprised 40,539 parity records of sows farrowed in the hot and humid season and 38,857 parity records of sows farrowed in the cold season.
The sows in these two datasets were categorized into three parity groups: parities 1 and 2, parities 3 to 5 , and parity 6 or higher. Parities 1 and 2 sows, parities 3 to 5 sows and parity 6 or higher sows represent young sows, mid-aged sows and aged sows, respectively.

\section{Climate data}

Climate data from 2007 to 2009 were downloaded from the climate statistics of 21 Japan Meteorological Agency weather stations [8]. The weather stations were located between latitude $20-45^{\circ} \mathrm{N}$ and longitude $136-148^{\circ} \mathrm{E}$ in the prefectural government office cities of the 21 prefecture districts in Japan where the studied herds were located. Mean ( $₫$ SEM) distance from each herd to the relevant weather station was $44.2 \pm 2.71$ $\mathrm{km}$, ranging between 1 and $110 \mathrm{~km}$. For each pregnant pig record, average daily values of maximum temperature $(\mathrm{HT})$, minimum temperature (LT) and relative humidity on the day of farrowing and one day before farrowing were coordinated with that pig's performance data from the PigCHAMP recording system. The 2-day period was chosen because it was assumed that the climatic conditions immediately before farrowing and during parturition are critical for the occurrence of a sow having SBP, and for the number of SBP. Producers were requested to record the farrowing date as the time when all the placenta had been delivered. Therefore, average values for the farrowing date and the previous day were used as peri-farrowing climatic conditions.

\section{Statistical analysis}

All statistical analyses were conducted using MLwiN software (MLwiN 2.26). Mixed models were used to account for the clustering of parity records within a sow and of sows within a herd. A multilevel logistic regression model with logit link was applied for binary outcome i.e., whether or not a sow had at least one SBP in a given litter (1 or 0) [19]. Also, a multilevel Poisson regression model with loglink was applied for the number of SBP. The statistical model for the number of SBP would have had threelevels of nested factors. However, initial analyses showed that compared with the estimated variance at the herd and sow level, the estimated variance at the sow level was much lower, and very close to zero $(<0.0001)$. Therefore, the sow level was omitted from the model for the number of SBP [20].

Two models were used for the occurrence of a sow having SBP and forthe number of SBP; one model was for sows farrowed in the hot and humid season and one was for sows farrowed in the cold season. The model for sows farrowed in the hot and humid season included the following factors as fixed effects: climatic factors of HT and relative humidity, parity groups and total pigs born. In the model for sows farrowed in the cold season, LT was used as a fixed effect in place of HT. The farrowing year was treated as a fixed effectin all models, and the herd was included as a random intercept. The sow nested within the herd wasalso included as a random intercept 
in the logistic regression models. Additionally, the quadratic and cubic expressions of the continuous variable factors were examined (i.e., $\mathrm{HT}$, LT, humidity and total number of pigs born), as were the two- and three-way interactions between the fixed effects. A significance level of $a=0.05$ (Wald's test) was appliedin MLwiN. The adequacy of the model assumptions for the random effects and the residuals (in the models that had residuals) was evaluated by visual inspection of normalprobability plots.

\section{Intraclass correlation coefficient}

To assess the variation in the occurrence of a sow having SBP that could be explained by the herd or sow, the intraclass correlation coefficients (ICC) were calculated by the following equations [4].

ICC (records within the same herd but different sows)

$$
=\frac{\sigma_{\text {Herd }}^{2}}{\sigma_{\text {Herd }}^{2}+\sigma_{\text {Sow }}^{2}+\left(\pi^{2} / 3\right)},
$$

$\sigma_{\text {Herd }}^{2}+\sigma_{\text {Sow }}^{2}+\left(\pi^{2} / 3\right)$
ICC (records within the same sow $)=\frac{\sigma_{\text {Herd }}^{2}+\sigma_{\text {Sow }}^{2}}{\sigma_{\text {Herd }}^{2}+\sigma_{\text {Sow }}^{2}+\left(\pi^{2} / 3\right)}$

where $\sigma_{\text {Herd }}^{2}$ is the between herd variation, $\sigma_{\text {Sow }}^{2}$ is the between sow variation, and $\pi^{2} / 3$ is the assumed variance at the individual record level. The $\sigma_{\text {Herd }}^{2}$ value was calculated for a sow that has average values for each climatic factor because $\sigma_{\text {Herd }}^{2}$ would vary by changing the climatic factors when the random slope effects at the herd level were significant. Also, with regard to the number of SBP, the ICC (proportion of variance at the herd level) as well as the variances at parity record level: $\sigma(1)$ and at herd level: $\sigma(2)$ were calculated by the following equations given by Dohoo et al. [4]:

ICC (records within the same herd) $=\frac{\sigma(2)}{\sigma(2)+\sigma(1)}$

$$
\sigma(1)=\exp \left(\beta \mathrm{X}+\sigma_{\text {Herd }}^{2} / 2\right)
$$

$$
\sigma(2)=\exp \left(2 \beta \mathrm{X}+2 \sigma_{\text {Herd }}^{2}\right)-\exp \left(2 \beta \mathrm{X}+\sigma_{\text {Herd }}^{2}\right)
$$

where $\beta \mathrm{X}$ is the predicted mean on a log scale.

\section{Results}

The occurrences ( \pm SEM) of sows having SBP during either the hot and humid season or the cold season were $49.6 \pm 0.17 \%$ and $48.8 \pm 0.18 \%$, respectively (Table 1 ). Also, mean SBP was $2.0 \pm 0.01$ pigs for sows that farrowed at least one SBP in either season. Mean (ranges) $\mathrm{HT}$ in the hot and humid season and LT in the cold season were $28.4(13.6 \text { to } 39.8)^{\circ} \mathrm{C}$ and 2.1 (-13.2 to 17.6$)^{\circ} \mathrm{C}$, respectively. Also, the mean values of relative humidity for the respective seasons were 73.4 (35 to 98)\% and 64.8 ( 25 to 99$) \%$.

The main effects of parity and total number of pigs born were found to be significant for an occurrence of a sow having SBP $(P<0.05)$ and having more SBPin either season $(P<0.05$; Tables 2 and 3 ). In both seasons, botha higher parity and a greater total number of pigs born were associated with a higher occurrence of a sow having SBP and with more SBP. For example, the occurrence of sows having SBP was 41.6$42.3 \%$ higher in sows that farrowed 16 pigs than in sows that farrowed only 8 pigs; furthermore they had $0.79-0.81$ more $\operatorname{SBP}(P<0.05$; Figures $1 \mathrm{~A}$ and $1 \mathrm{~B})$.

In the hot and humid season, there was a two-way interaction between $\mathrm{HT}$ and parity groups for an occurrence of a sow having SBP $(P<0.05$; Table 2$)$. As HT increased from 25 to $30^{\circ} \mathrm{C}$ the occurrences of SBP in parities 3-5 sows and in parity 6 or higher sows increased by 2.1 and $2.7 \%$, respectively $(P<0.05$; Figure 2A). However, there was no association between HT and occurrences of parities 1-2 sows having SBP $(P=0.73)$. There was also no two-way interaction between $\mathrm{HT}$ and total number of pigs born for the occurrence of sows having SBP $(\mathrm{P}=0.87)$. For sows that farrowed at least one $\mathrm{SBP}$, there was an association between higher HT and more SBP $(\mathrm{P}<0.05)$. For example, a sow exposed to $30^{\circ} \mathrm{C}$ had 0.04 more SBP than

\begin{tabular}{|c|c|c|c|c|}
\hline \multirow[t]{2}{*}{ Measurements } & \multirow[t]{2}{*}{$\mathbf{N}^{1}$} & \multirow[t]{2}{*}{ Mean \pm SEM } & \multicolumn{2}{|c|}{ Range } \\
\hline & & & Minimum & Maximum \\
\hline \multicolumn{5}{|l|}{57,751 sows farrowed in hot and humid season } \\
\hline Parity & 81,672 & $3.4 \pm 0.01$ & 1 & 15 \\
\hline Total pigs born, pigs & 81,672 & $12.2 \pm 0.01$ & 1 & 33 \\
\hline Percentage of sows having stillborn piglets, $\%$ & 81,672 & $49.6 \pm 0.17$ & -- & -- \\
\hline Number of stillborn piglets, pigs ${ }^{2}$ & 40,539 & $2.0 \pm 0.01$ & 1 & 22 \\
\hline \multicolumn{5}{|l|}{55,705 sows farrowed in cold season } \\
\hline Parity & 79,627 & $3.4 \pm 0.01$ & 1 & 14 \\
\hline Total pigs born, pigs & 79,627 & $12.0 \pm 0.01$ & 1 & 26 \\
\hline Percentage of sows having stillborn piglets, $\%$ & 79,627 & $48.8 \pm 0.18$ & -- & -- \\
\hline Number of stillborn piglets, pigs ${ }^{2}$ & 38,857 & $2.0 \pm 0.01$ & 1 & 25 \\
\hline
\end{tabular}

Table 1. Reproductive data for sows in $\mathbf{1 0 1}$ herds farrowed in either hot and humid (June to September) or cold seasons (December to March).

${ }^{1} \mathrm{~N}$ represents the total number of parity records.

${ }^{2}$ Omitted data were records of sows with no stillborn piglets. 
Tani et al. Veterinary Medicine and Animal Sciences 2016,

Table 2. Estimates of climatic factors, other fixed effects and random effect variance included in the final models ${ }^{1}$ for the probability of a sow having stillborn piglets and for the number of stillborn piglets $^{2}$ during the hot and humid season (June to September).

\begin{tabular}{|c|c|c|c|c|}
\hline \multirow{2}{*}{$\begin{array}{l}\text { Hot and humid season } \\
\text { Fixed effects (factors) }{ }^{3} \text { and variance }\end{array}$} & \multicolumn{2}{|c|}{$\begin{array}{l}\text { Probability of a sow having } \\
\text { stillborn piglets }\end{array}$} & \multicolumn{2}{|c|}{ Number of stillborn piglets } \\
\hline & Estimate $( \pm$ SE $)$ & P-value & Estimate $( \pm \mathrm{SE})$ & P-value \\
\hline Intercept & $-0.4213(0.0392)$ & $<0.01$ & $0.5121(0.0125)$ & $<0.01$ \\
\hline Maximum temperature (HT) & $0.0014(0.0041)$ & 0.73 & $0.0050(0.0011)$ & $<0.01$ \\
\hline Relative humidity (RH) & $0.0024(0.0011)$ & 0.02 & $0.0011(0.0005)$ & 0.03 \\
\hline \multicolumn{5}{|l|}{ Parity groups (Parity) } \\
\hline Parities 3 to 5 & $0.3334(0.0199)$ & $<0.01$ & $0.0672(0.0087)$ & $<0.01$ \\
\hline Parity 6 or higher & $0.9063(0.0283)$ & $<0.01$ & $0.2385(0.0103)$ & $<0.01$ \\
\hline \multicolumn{5}{|l|}{ HT x Parity } \\
\hline HT $\mathrm{x}$ Parities 3 to 5 & $0.0152(0.0043)$ & $<0.01$ & -- & -- \\
\hline HT x Parity 6 or higher & $0.0217(0.0061)$ & $<0.01$ & -- & -- \\
\hline Total number of pigs born (TPB) & $0.2317(0.0054)$ & $<0.01$ & $0.0549(0.0023)$ & $<0.01$ \\
\hline TPB-squared & $0.0092(0.0011)$ & $<0.01$ & $0.0033(0.0002)$ & $<0.01$ \\
\hline TPB-cubed & $-0.0003(0.0001)$ & $<0.01$ & -- & -- \\
\hline $\mathrm{RH} \times \mathrm{TPB}$ & $0.0006(0.0003)$ & 0.03 & $0.0003(0.0001)$ & 0.04 \\
\hline \multicolumn{5}{|l|}{ Parity $x$ TPB } \\
\hline Parities 3 to $5 \mathrm{x}$ TPB & $0.0172(0.0062)$ & $<0.01$ & $0.0106(0.0030)$ & $<0.01$ \\
\hline Parity 6 or higher $\mathrm{x}$ TPB & $0.0452(0.0086)$ & $<0.01$ & $0.0208(0.0034)$ & $<0.01$ \\
\hline \multicolumn{5}{|l|}{ Parity $x$ TPB-squared } \\
\hline Parities 3 to $5 \mathrm{x}$ TPB-squared & $-0.0038(0.0013)$ & $<0.01$ & -- & -- \\
\hline Parity 6 or higher x TPB-squared & $-0.0069(0.0018)$ & $<0.01$ & -- & -- \\
\hline Intercept variance at herd level & $0.1157(0.0180)$ & -- & $0.0070(0.0013)$ & -- \\
\hline Intercept variance at sow level & $0.1156(0.0188)$ & -- & -- & -- \\
\hline $\begin{array}{l}\text { Intraclass correlation coefficient (ICC; } \\
\text { records within the same herd), \% }\end{array}$ & 3.3 & -- & 1.2 & -- \\
\hline ICC (records within the same sow), \% & 6.6 & -- & -- & -- \\
\hline
\end{tabular}

${ }^{1}$ Logistic regression and Poisson regression models were used respectively for the probability of a sow having stillborn piglets and for the number of stillborn piglets.

${ }^{2}$ Omitted data were records of sows with no stillborn piglets.

${ }^{3}$ Reference category was the parities 1 and 2 sow group.
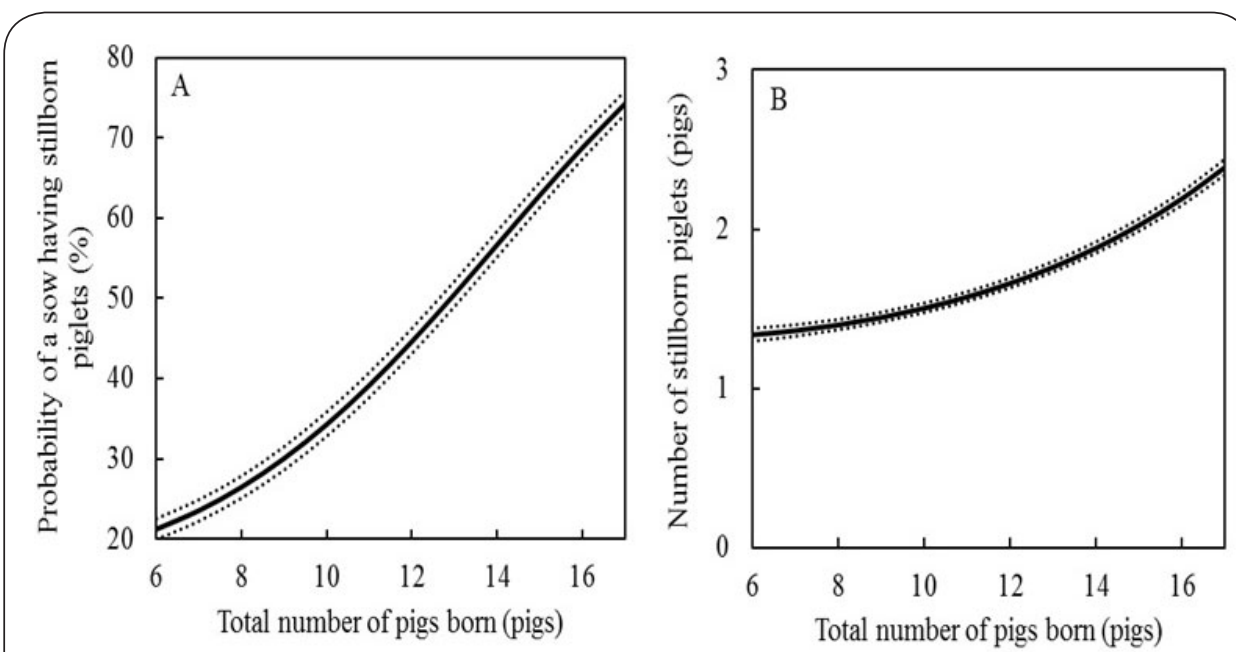

Figure 1. Effect of total pigs born on probability of a sow having stillborn piglets (A) and on the number of stillborn piglets (B), for sows farrowed from June to September. The dotted lines represent the $95 \%$ confidence intervals for predicted means. 
Tani et al. Veterinary Medicine and Animal Sciences 2016,

Table 3. Estimates of climatic factors, other fixed effects and random effect variance included in the final models ${ }^{1}$ for the probability of a sow having stillborn piglets and for the number of stillborn piglets $^{2}$ during the cold season (December to March).

\begin{tabular}{|c|c|c|c|c|}
\hline \multirow{2}{*}{$\begin{array}{l}\text { Cold season } \\
\text { Fixed effects (factors) }{ }^{3} \text { and variance } \\
\end{array}$} & \multicolumn{2}{|c|}{$\begin{array}{l}\text { Probability of a sow having } \\
\text { stillborn piglets }\end{array}$} & \multicolumn{2}{|c|}{$\begin{array}{l}\text { Number of stillborn } \\
\text { piglets }\end{array}$} \\
\hline & Estimate $( \pm$ SE) & P-value & Estimate $( \pm$ SE $)$ & P-value \\
\hline Intercept & $-0.3920(0.0414)$ & $<0.01$ & $0.5329(0.0135)$ & $<0.01$ \\
\hline Minimum temperature $(\mathrm{LT})^{4}$ & $-0.0198(0.0039)$ & $<0.01$ & $-0.0052(0.0013)$ & $<0.01$ \\
\hline \multicolumn{5}{|l|}{ Parity groups (Parity) } \\
\hline Parities 3 to 5 & $0.2663(0.0171)$ & $<0.01$ & $0.0351(0.0088)$ & $<0.01$ \\
\hline Parity 6 or higher & $0.8290(0.0246)$ & $<0.01$ & $0.1908(0.0105)$ & $<0.01$ \\
\hline \multicolumn{5}{|l|}{ LT x Parity } \\
\hline LT $x$ Parities 3 to 5 & $0.0120(0.0048)$ & 0.01 & -- & -- \\
\hline LT x Parity 6 or higher & $0.0076(0.0063)$ & 0.23 & -- & -- \\
\hline Total pigs born (TPB) & $0.2193(0.0044)$ & $<0.01$ & $0.0574(0.0023)$ & $<0.01$ \\
\hline TPB-squared & $0.0059(0.0006)$ & $<0.01$ & $0.0032(0.0002)$ & $<0.01$ \\
\hline LT x TPB & $-0.0032(0.0008)$ & $<0.01$ & $-0.0010(0.0003)$ & $<0.01$ \\
\hline \multicolumn{5}{|l|}{ Parity $x$ TPB } \\
\hline Parities 3 to $5 \mathrm{x}$ TPB & $0.0196(0.0058)$ & $<0.01$ & $0.0045(0.0029)$ & 0.12 \\
\hline Parity 6 or higher x TPB & $0.0445(0.0081)$ & $<0.01$ & $0.0200(0.0034)$ & $<0.01$ \\
\hline Intercept variance at herd level & $0.1354(0.0208)$ & -- & $0.0093(0.0017)$ & -- \\
\hline Intercept variance at sow level & $0.1194(0.0190)$ & -- & -- & -- \\
\hline $\begin{array}{l}\text { Intraclass correlation coefficient } \\
\text { (ICC; records within the same herd), \% }\end{array}$ & 3.8 & -- & 1.7 & -- \\
\hline ICC (records within the same sow), \% & 7.2 & -- & -- & -- \\
\hline
\end{tabular}

${ }^{1}$ Logistic regression and Poisson regression models were used respectively for the probability of a sow having stillborn piglets and for the number of stillborn piglets.

${ }^{2}$ Omitted data were records of sows with no stillborn piglets.

${ }^{3}$ Reference category was the parities 1 and 2 sow group.
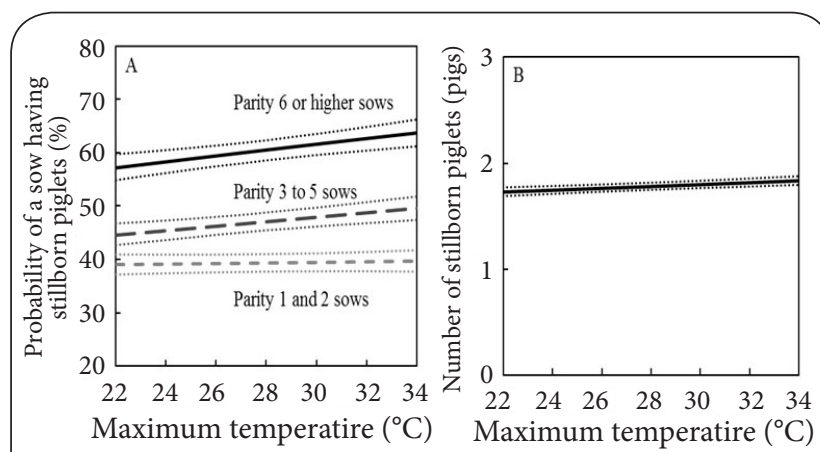

Figure 2. Effect of maximum temperature (HT) on probabilities of sows in different parity groups ${ }^{1,2}$ having stillborn piglets (A) and on the number of stillborn piglets (B), from June to September. ${ }^{1}$ The regression coefficients of the HT term for sows in parity 3 or higher differed from zero $(\mathrm{P}<0.05) .{ }^{2}$ The regression coefficient of the HT term for sows in parities 1 and 2 did not differ from zero $(\mathrm{P}=0.73)$. The dotted lines represent the $95 \%$ confidence intervals for predicted means.

one exposed to $25^{\circ} \mathrm{C}(\mathrm{P}<0.05$; Figure 2B). No two-way interactions between $\mathrm{HT}$ and production factors were found for the number of $S B P(P \geq 0.06)$.
In the hot and humid season, there were two-way interactions between relative humidity and total number of pigs born for the occurrence of a sow having SBP and for the number of SBP $(P<0.05)$. As relative humidity increased from 60 to $85 \%$, the occurrence of a sow that farrowed 16 pigs (90th percentile) having SBP increased by $2.5 \%$; the number of SBP for such sows also increased by 0.10 pigs $(P<0.05$; Figures $3 A$ and $3 B$ ). However, for pigs that farrowed only 8 pigs (10th percentile), relative humidity was not associated with either the occurrence of a sow having $S B P(P=0.87)$ or with the number of SBP $(P=0.73)$. There were no two-way interactions between relative humidity and parity groups for either the occurrence of a sow having SBP $(P=0.11)$ or for the number of $\operatorname{SBP}(P=0.67)$. Also, there were no two-way interactions between $\mathrm{HT}$ and relative humidity for either the occurrence of a sow having SBP $(P=0.41)$ or for the number of SBP $(P=0.24)$.

In the cold season, there was a two-way interaction between LT and parity groups with regard to the occurrence of a sow having SBP $(\mathrm{P}<0.05$; Table 3$)$. However, there was no such two-way interaction for the number of SBP $(P=0.67)$. The occurrences of sows in any parity group having $S B P$ increased by $0.9-2.2 \%$ as $L T$ decreased from 5 to $0^{\circ} \mathrm{C}(\mathrm{P}<0.05$; Figure 4$)$. Two-way interactions between LT and total number of pigs 
Tani et al. Veterinary Medicine and Animal Sciences 2016,
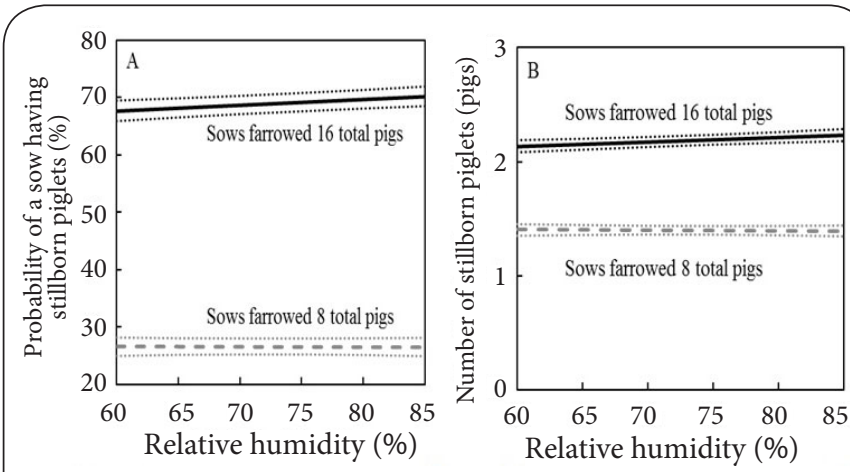

Figure 3. Effect of relative humidity $(\mathrm{RH})$ on probabilities of sows having stillborn piglets (A) and on the number of stillborn piglets (B), for sows that farrowed 8 or 16 pigs (10th or 90 th percentile, respectively) ${ }^{1,2}$ from June to September. ${ }^{1}$ The regression coefficients of the $\mathrm{RH}$ term for sows that farrowed 8 pigs did not differ from zero $(\mathrm{P}>0.73) .{ }^{2}$ The regression coefficients of the $\mathrm{RH}$ term for sows that farrowed 16 pigs differed from zero $(\mathrm{P}<0.05)$. The dotted lines represent the $95 \%$ confidence intervals for predicted means.

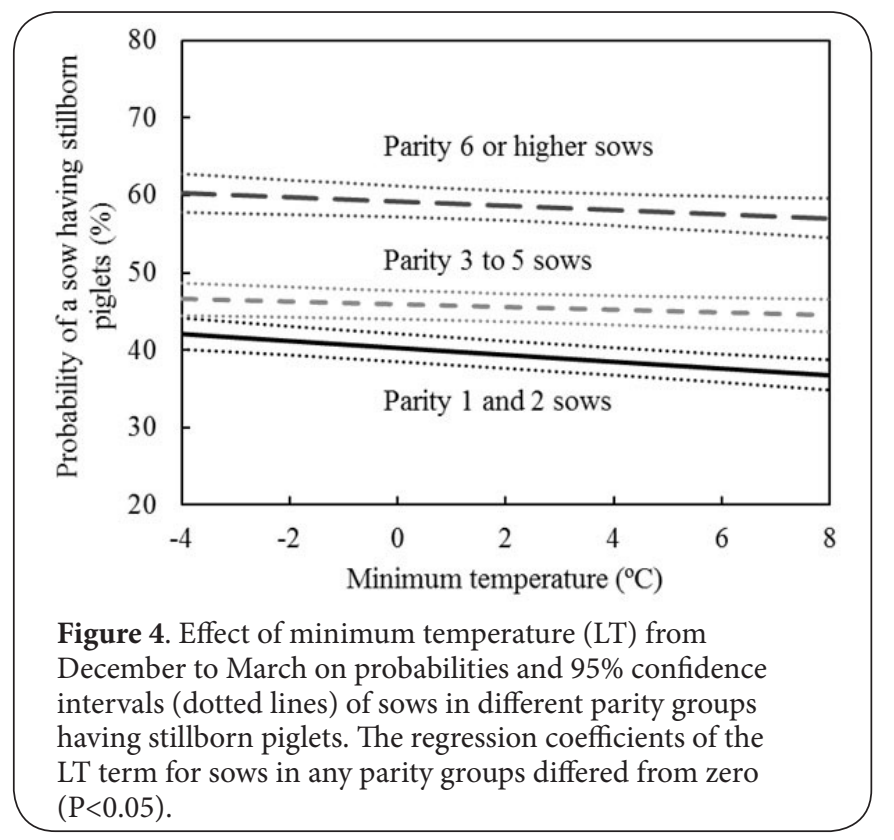

born were found for both the occurrence of a sow having SBP and for the number of SBP $(P<0.05)$. As LT decreased from 5 to $0^{\circ} \mathrm{C}$, the occurrences of sows that farrowed 16 pigs having SBP increased by $2.7 \%$, and the number of SBP for such sows increased by 0.09 pigs $(P<0.05$; Figure $5 A$ and $5 B$ ). However, LT was not associated with either the occurrence of sows having SBP $(P=0.89)$ or with the number of SBP for sows that farrowed 8 pigs $(\mathrm{P}=0.94)$. Also, there were no associations between relative humidity in the cold season and either the occurrence of a sow having SBP $(P=0.19)$ or the number of SBP $(\mathrm{P}=0.94)$.

With regard to the ICC, the respective herd and sow effects
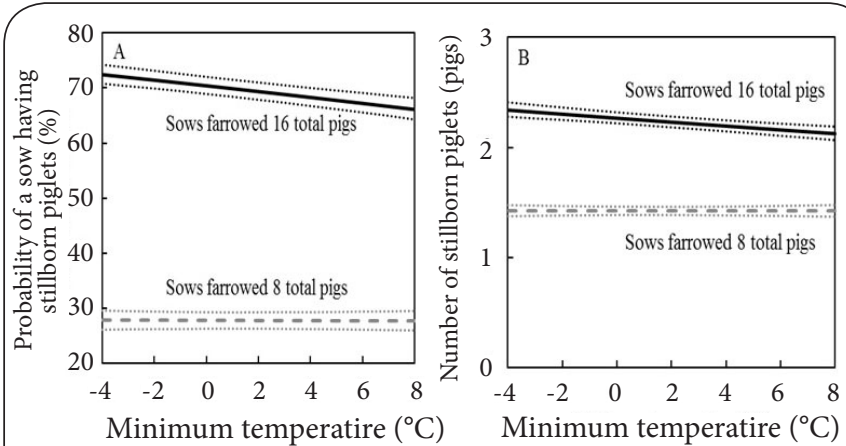

Figure 5. Effect of minimum temperature (LT) from December to March on probabilities of sows having stillborn piglets (A) and on the number of stillborn piglets (B) for sows that farrowed 8 and 16 pigs (10th or 90th percentile, respectively) $)^{1,2}$. ${ }^{1}$ The regression coefficients of the LT term for sows that farrowed 8 pigs did not differ from zero $(\mathrm{P}=0.89)$. ${ }^{2}$ The regression coefficients of the LT term for sows that farrowed 16 pigs differed from zero $(\mathrm{P}<0.05)$. The dotted lines represent the $95 \%$ confidence intervals for predicted means.

explained $3.3-3.8$ and $6.6-7.2 \%$ of the total variation inthe occurrence of a sow having SBP in either season. Also, the ICC of SBP was $1.2-1.7 \%$ for a sow that had average values for each fixed effect variable.

\section{Discussion}

The present study is consistent with previous studies showing that higher parity and greater total numbers of pigs born are associated with a high occurrence of a sow having SBP and witha greaternumber of SBP $[3,19]$. Our study has also added quantitative information showing that the negative effect of HT on the occurrences of sows having SBP was greatest for parity 6 or higher sows. The greater susceptibility of high parity peripartum sows to high HT could be related to their poor uterine muscle tone [14]. Our results suggest that higher parity sows with poor uterine muscle are likely to have more SBP under high HT conditions. Furthermore, sows under elevated ambient temperature around farrowing also tend to have high cortisol concentrations in the peripheral blood [11], which counteracts the effect of oxytocin that usually stimulates contraction of smooth muscle in the uterus [15]. This would likely cause heat-stressed sows in higher parity to have prolonged parturition, and consequently have SBP due to hypoxia or asphyxia [6].

The present study is the first report to show that lower perifarrowing LT is associated with both a higher occurrence of a sow having SBP and with sows having more SBP. It is possible that sows exposed to low LT in winter could have a longer duration of farrowing that increases the risk of SBP, similar to the effect on heat-stressed sows in the summer season. This finding is supported by a previous study which showed that finishing pigs housedat $5^{\circ} \mathrm{C}$ had higher plasma cortisol concentrations and higher adrenal weights compared to pigs 
housedat $20^{\circ} \mathrm{C}$ [12]. Also, our study showed that the negative effects of LT on the occurrences of sows having SBP were greater in low parity sows than inmid-parity sows. The reason for the greater effects in low parity sows could be explained by their immature body and uterus or their narrow birth canal [14]. Furthermore, prolonged or intermittent asphyxia in utero and during delivery weakens piglets and renders them less capable of adapting to cold stress [1]. Therefore, the piglets recorded as SBP would also include piglets that died immediately after farrowing when they were suddenly exposed to fluctuating and cold temperatures [5].

The negative effects of climatic factors on the occurrence of a sow having SBP and on the number of SBP were greater in sows that had a greater total number of pigs born. An increase in the total number of pigs born is directly associated with prolonged farrowing [18]. It appears that sows that have farrowed more pigs are less able to adapt to climatic conditions in either season than sows that have farrowed fewer pigs. Sows that farrowed many piglets were likely to have had prolonged peripartum periods and some of them would have been weary from the prolonged peripartum period or might have dystocia. Additionally, our study indicates that in sows that have farrowed high numbers of pigs in summer, humidity affects both the occurrence of SBP and the number of SBP when the temperature exceeds a certain level. Our finding is consistent with a Thai study showing that a high ambient temperature decreases total number of pigs bornin sows when relative humidity is high [16].

It should be noted that in our study the influences of both parity and total number of pigs born on the occurrences of sows having SBP and on the number of SBP were larger than the influence of climatic conditions. Also, the ICC for sow variance (i.e., repeatability) of $6.6-7.2 \%$ was relatively low. This low repeatability and the high influence of parity and total number of pigs born on the two SBP variables indicate that it is important to monitor and assist the farrowing process of sows in high parity and of sows expected to give birth to large litters [19]. Additionally, the relatively low ICC of 1.2-3.7\% for herd variance indicates that there were few unexplained effects of the herd on either the occurrence of a sow having SBP or on the number of SBP.

\section{Conclusion}

Our study shows that high HT and high humidity in summer, and also low LT in winter appear to be critical factors for SBP occurrences and for the number of SBP, especially forhigh parity sows and for sows that have farrowed more pigs. Therefore, it is recommended that cooling systems are installed to minimize the risks to these females in hot and humid seasons, and that heaters and thick insulation are installed to minimize the risk factors in cold seasons.

The present study is an observational study using commercial herd data and also climate data recorded at meteorological stations. Also, the resultscould be biased by herd health, nutrition and genotype which were not measured. However, even with such limitations, this research provides valuable information about the relationship between climate and SBP measurements for swine producers and veterinarians.

\section{Competing interests}

The authors declare that they have no competing interests.

Authors' contributions

\begin{tabular}{|l|c|c|c|}
\hline Authors' contributions & ST & RI & YK \\
\hline Research concept and design & -- & $\checkmark$ & $\checkmark$ \\
\hline Collection and/or assembly of data & -- & $\checkmark$ & -- \\
\hline Data analysis and interpretation & $\checkmark$ & $\checkmark$ & -- \\
\hline Writing the article & $\checkmark$ & $\checkmark$ & -- \\
\hline Critical revision of the article & $\checkmark$ & -- & $\checkmark$ \\
\hline Final approval of article & -- & -- & $\checkmark$ \\
\hline Statistical analysis & $\checkmark$ & $\checkmark$ & -- \\
\hline
\end{tabular}

\section{Acknowledgement}

We express thanks to Dr. I. McTaggart for his critical review of this manuscript. This work was supported by Research Project Grants from Meiji University.

\section{Publication history}

Editors: Hirofumi Akari, Kyoto University, Japan. Franz-Josef Kaup, German Primate Center, Germany. Ralf Blank, University of Kiel, Germany.

Received: 10-Mar-2016 Final Revised: 14-Apr-2016

Accepted: 20-Apr-2016 Published: 25-Apr-2016

\section{References}

1. Alonso-Spilsbury M, Mota-Rojas D, Villanueva-Garcia D, Martinez-Burnes J, Orozco H, Ramirez-Necoechea R, Mayagoitia AL and Trujillo ME. Perinatal asphyxia pathophysiology in pig and human: a review. Anim Reprod Sci. 2005; 90:1-30. | Article | PubMed

2. Bloemhof S, van der Waaij EH, Merks JW and Knol EF. Sow line differences in heat stress tolerance expressed in reproductive performance traits. J Anim Sci. 2008; 86:3330-7. | Article | PubMed

3. Canario L, Cantoni E, Le Bihan E, Caritez JC, Billon Y, Bidanel JP and Foulley JL. Between-breed variability of stillbirth and its relationship with sow and piglet characteristics. J Anim Sci. 2006; 84:3185-96. | Article I PubMed

4. Dohoo IR, Martin SW and Stryhn H. Veterinary Epidemiologic Research, 2nd ed. VER Inc. Charlottetown. 2009; 579-606.

5. Glastonbury JR. Preweaning mortality in the pig. Pathological findings in piglets dying between birth and weaning. Aust Vet J. 1977; 53:310-4. | Article | PubMed

6. Herpin P, Hulin JC, Le Dividich J and Fillaut M. Effect of oxygen inhalation at birth on the reduction of early postnatal mortality in pigs. J Anim Sci. 2001; 79:5-10. I Article I PubMed

7. Iida $R$ and Koketsu $Y$. Interactions between climatic and production factors on returns of female pigs to service during summer in Japanese commercial breeding herds. Theriogenology. 2013; 80:487-93. | Article I PubMed

8. JMA, 2013. Japan Meteorological Agency. 2013. | Website

9. Leenhouwers JI, Wissink P, van der Lende T, Paridaans $\mathrm{H}$ and Knol EF. Stillbirth in the pig in relation to genetic merit for farrowing survival. $J$ Anim Sci. 2003; 81:2419-24. | Article | PubMed

10. Lucia T, Jr., Correa MN, Deschamps JC, Bianchi I, Donin MA, Machado AC, Meincke W and Matheus JE. Risk factors for stillbirths in two swine farms in the south of Brazil. Prev Vet Med. 2002; 53:285-92. | Article | PubMed 
11. Machado-Neto R, Graves $\mathrm{CN}$ and Curtis SE. Immunoglobulins in piglets from sows heat-stressed prepartum. J Anim Sci. 1987; 65:445-55. I Article I PubMed

12. Nienaber JA, Hahna GL, Klemcke HG, Becker BA and Blecha F. Cyclic temperature effects on growing-finishing swine. J. Therm. Biol. 1989; 14:233-237.

13. Odehnalova S, Vinkler A, Novak P and Drabek J. The dynamics of changes in selected parameters in relation to different air temperature in the farrowing house for sows. Czech. J. Anim. Sci. 2008; 53:195-203. | Article

14. Pejsak $Z$. Some pharmacological methods to reduce intrapartum death of piglets. Pig News and Information. 1984; 5:35-37. | Article

15. Gang W. Review of Medical Physiology 19th edn. Applton \& Lange. Stamford. 1999; 235-236.

16. Suriyasomboon A, Lundeheim N, Kunavongkrit A and Einarsson S. Effect of temperature and humidity on reproductive performance of crossbred sows in Thailand. Theriogenology. 2006; 65:606-28. | Article I PubMed

17. Tummaruk P. Effects of season, outdoor climate and photo period on age at first observed estrus in Landrace $\mathrm{x}$ Yorkshire crossbred gilts in Thailand. Livest. Sci. 2012; 144:163-172. | Article

18. van Rens BT and van der Lende T. Parturition in gilts: duration of farrowing, birth intervals and placenta expulsion in relation to maternal, piglet and placental traits. Theriogenology. 2004; 62:331-52. | Article I PubMed

19. Vanderhaeghe C, Dewulf J, de Kruif A and Maes D. Non-infectious factors associated with stillbirth in pigs: a review. Anim Reprod Sci. 2013; 139:76-88. | Article | PubMed

20. Vigre $H$, Dohoo IR, Stryhn $H$ and Busch ME. Intra-unit correlations in seroconversion to Actinobacillus pleuropneumoniae and Mycoplasma hyopneumoniae at different levels in Danish multi-site pig production facilities. Prev Vet Med. 2004; 63:9-28. | Article | PubMed

\section{Citation:}

Tani S, Iida R and Koketsu Y. Climatic factors, parity and total number of pigs born associated with occurrences and numbers of stillborn piglets during hot or cold seasons in breeding herds. Vet Med Anim Sci. 2016; 4:3.

http://dx.doi.org/10.7243/2054-3425-4-3 